\title{
Dampak Riba mendatangkan Kebinasaan: Sebuah Tinjaun Hadis
}

\author{
Weni Luthfiani Fauziah \\ Jurusan Ilmu Hadis, Fakultas Ushuluddin \\ UIN Sunan Gunung Djati Bandung \\ Wenifauziah28@gmail.com
}

\begin{abstract}
The purpose of this study is to discuss the hadith about the prohibition of usury. This research method uses a qualitative type through literature study with content analysis. The results and discussion of this study include general views on usury, hadith about usury, and prohibitions and threats of usury behavior in the perspective of hadith. This study concludes that usury in the hadith is prohibited and forbidden by Allah and His Messenger and is included in the case that can destroy.
\end{abstract}

Keywords: Hadith, Riba, Syarah

\begin{abstract}
Abstrak
Tujuan penelitian ini adalah membahas hadis tentang larangan riba. Metode penelitian ini menggunakan jenis kualitatif melalui studi pustaka dengan analisis isi. Hasil dan pembahasan penelitian ini meliputi pandangan umum tentang riba, hadis tentang riba, dan larangan dan ancaman perilaku riba dalam perspektif hadis. Penelitian ini menyimpulkan bahwa riba dalam hadis itu dilarang dan diharamkan oleh Allah dan Rasul-Nya dan termasuk ke dalam perkara yang dapat membinasakan.
\end{abstract}

Kata kunci: Hadis, Riba, Syarah

\section{Pendahuluan}

Riba adalah pengambilan tambahan, baik dalam transaksi jual beli maupun pinjam meminjam secara bathil atau bertentangan dengan prinsip muamalah Islam (Naufal, 2019). Begitu banyak larangan mengenai riba yang terkandung di dalam Al-Qur'an maupun hadis. Hal ini untuk menjaga kemaslahatan hidup manusia dari kerusakan moral (akhlak), sosial dan ekonominya (Sari, 2018). Namun praktik riba ini membutuhkan perhatian yang besar agar tidak menjadi kebiasaan yang kurang baik di tengah masyarakat. Oleh karena itu, penting sekali mempelajari dalil-dalil tentang 
Jurnal Riset Agama, Volume 1, Nomor 1 (April 2021): 197-208

Weni Luthfiani Fauziah/Dampak Riba mendatangkan Kebinasaan: Sebuah Tinjaun Hadis

larangan riba sehingga kita terhindar dari riba yang telah dilarang oleh Allah Swt.

Sejumlah pakar telah telah melakukan penelitian berkenaan dengan larangan riba sebagaimana dalam tinjauan pustaka penelitian ini. Antara lain Tho'in, Muhammad (2016), Judul " Larangan Riba dalam Teks dan Konteks (Studi atas Hadis Riwayat Muslim tentang Pelaknatan Riba)," Penerbit Jurnal Ilmiah Ekonomi Islam LPPM STIE AAS Surakarta. Artikel ini menggunakan teori ilmu hadis yang merupakan jenis penelitian kualitatif dengan pendekatan kajian kitab. Hasil dan pembahasan artikel ini adalah hadis-hadis berkenaan dengan ancaman pelaku riba dan pelaknatan riba dakan teks dan konteks (Tho'in, 2016). Ulum, Khozanul (2016), Judul " Hakikat Keharaman Riba dalam Islam," Penerbit Jurnal Ekonomi Syariah Universitas Islam Lamongan. Penelitian ini menggunakan metode analisis kritis dengan menggunakan kombinasi pola pikir yang didasarkan pada kenyataan dengan iman. Hasil dan pembahasan penelitian ini adalah tentang hakikat realitas transaksi, dengan membandingkan realitas dengan argumen dan pendapat yang berkaitan dengan apakah bunga yang diterapkan saat ini termasuk riba dan bagaimana bahaya mengkonsumsi hasil riba (Ulum, 2016). Munir, Misbahul (2017), Judul "Kosep Riba dalam Islam: Analisis Tematik terhadap Konsep Riba dalam Al-Qur'an dan Hadis," Penerbit Research Report Fakultas Ekonomi Universitas Islam Negeri Maulana Malik Ibrahim Malang. Penelitian ini menggunakan metode pendekatan kontekstual dalam melakukan analisis dan interpretasi terhadap ayat Al-Qur'an dan hadis-hadis Nabi Saw. Penelitian ini menyimpulkan bahwa riba diharamkan secara jelas dan tegas, baik dalam Al-Qur'an maupun sunnah. Umat Islam dilarang mengambil riba apa pun jenisnya (Munir, 2017).

Berbagai penelitian terdahulu berhraga dalam penyusunan kerangka berfikir penelitian ini. Riba adalah pengambilan tambahan, baik dalam transaksi jual beli maupun pinjam meminjam secara bathil atau bertentangan dengan prinsip muamalah Islam (Naufal, 2019). Riba identik dengan bunga bank atau rente, sering kita dengar di tengah-tengah masyarakat bahwa rente disamakan dengan riba (Sar'an, 2014). Tambahan atas sejumlah pinjaman ketika pinjaman itu dibayar dalam tenggang waktu tertentu 'iwadh (imbalan) adalah riba (Setyawati, 2017). Hadis tentang riba tersebar dalam Al- Kutub al-This'ah (Milah, 2016). Hadis tersebut merupakan hadis yang shahih yang disepakati oleh para ulama hadis (Tho'in, 2016). Jika ditinjau dari kitab hadis yang banyak menerangkan tentang hadis yang telah dijelaskan maka hadis tentang riba dikatakan hadis shohih (Milah, 2016). Nabi Muhammad Saw. telah menegaskan dengan bahasa yang keras untuk memperingatkan umat manusia dan juga umat Islam mengenai riba (Setyawati, 2017). Nabi Muhammad Saw. juga menegaskan dinyatakan perang dari Allah dan rasul-Nya yang berkenaan 
Jurnal Riset Agama, Volume 1, Nomor 1 (April 2021): 197-208

Weni Luthfiani Fauziah/Dampak Riba mendatangkan Kebinasaan: Sebuah Tinjaun Hadis

dengan larangan riba (Setyawati, 2017). Di dalam hadis dijelaskan bahwa ada beberapa yang tekait dengan orang-orang yang bertransaksi riba ini akan mendapatkan laknat dari Allah Swt. (Setyawati, 2017).

Berdasarkan paparan di atas, penulis berusaha menyusun formula penelitian, yaitu rumusan masalah, pertanyaan penelitian, dan tujuan penelitian (Darmalaksana, 2020). Rumusan masalah penelitian ini adalah terdapat penjelasan hadis tentang larangan riba. Pertanyaan utama penelitian ini ialah bagaimana penjelasan hadis tentang larangan riba. Tujuan penelitian ini yakni membahas penjelasan hadis tentang larangan dan ancaman perilaku riba. Penelitian ini diharapkan memiliki manfaat bagi pengayaan khazanah pengetahuan Islam.

\section{Metode Penelitian}

Penelitian ini merupakan jenis kualitatif melalui studi pustaka dengan menerapkan analisis isi (Darmalaksana, 2020).

\section{Hasil dan Pembahasan Penelitian}

Hasil dan pembahasan penelitian di bawah ini.

\section{Pandangan Umum tentang Riba}

Kata riba berasal dari bahasa Arab, secara etimologis berarti tambahan (azziyadah), berkembang (an-numuw), membesar (al-'uluw) dan meningkat (alirtifa') (Setyawati, 2017). Sedangkan secara terminologi riba adalah pengambilan tambahan, baik dalam transaksi jual beli maupun pinjam meminjam secara bathil atau bertentangan dengan prinsip muamalah Islam (Naufal, 2019). Menurut A. Hasan, riba adalah suatu tambahan yang diharamkan di dalam urusan pinjam meminjam. Sedangkan menurut jumhur ulama prinsip utama dalam riba adalah penambahan, yaitu penambahan atas pokok tanpa adanya transaksi bisnis riil.

Para ulama mengemukakan definisi tentang riba. Menurut Hanabilah riba merupakan tambahan pada suatu barang tertentu. Menurut Syafi'iyah riba merupakan akad pada pengganti tertentu yang tidak sepadan dalam timbangan syar'i, baik dalam akad kontan maupun kredit dalam penggantinya atau salah satunya. Dan yang dimaksud pengganti tertentu adalah barang-barang ribawi. Sedangkan yang dimaksud dengan tidak sepadan adalah adanya tambahan pada salah satu pengganti atau tidak adanya persamaan. Dan timbangan syar'i maksudnya adalah takaran atau timbangan. Sementara dikaitkan dengan akad kontan jika sekiranya diketahui kesepadanan pada keduanya setelah akad. Definisi riba menurut Hanafiyah yaitu kelebihan yang menjadi hak dari salah satu pihak dalam transaksi, terlepas dari pengganti yang disyaratkan. Artinya tambahan bagi salah satu pihak hanya dalam akad-akad transaksi saja. Maka hibah tidak 
Jurnal Riset Agama, Volume 1, Nomor 1 (April 2021): 197-208

Weni Luthfiani Fauziah/Dampak Riba mendatangkan Kebinasaan: Sebuah Tinjaun Hadis

termasuk, karena bukan transaksi. Dan tambahan di sini tidak ada penggantinya atau penyeimbangnya, maka tambahan itu adalah riba. Menurut Ibn 'Abbas riba adalah tambahan pada akhir jual beli setelah tempo berakhir seperti pada awal jual beli ketika dijual dengan tempo. Dan riba menurut Muhammad 'Ali ash-Shabuni yaitu tambahan yang diambil oleh pemberi pinjaman dari si peminjam karena adanya tempo (Naufal, 2019). Berdasarkan beberapa pengetian yang telah diuraikan tersebut maka secara umum riba adalah pengambilan tambahan baik dalam transaksi jual beli maupun pinjam meminjam secara bathil atau bertentangan dengan prinsip muamalat dalam Islam (Setyawati, 2017).

Riba identik dengan bunga bank atau rente, sering kita dengar di tengah-tengah masyarakat bahwa rente disamakan dengan riba (Sar'an, 2014). Hal ini disebabkan rente dan riba merupakan bunga uang. Dalam prakteknya, rente merupakan keuntungan yang diperoleh bank atas jasanya dalam meminjamkan uang kepada debitur dengan dalih untuk usaha produktif sehingga uang pinjaman tersebut usahanya menjadi maju dan lancar dan keuntungan yang diperoleh semakin besar. Tetapi dalam akad kedua belah pihak sama sama sepakat atas keuntungan yang akan diperoleh pihak bank. Riba sangat erat kaitannya dengan bank konvensional, karena dalam praktiknya banyak ditemui transaksi-transaksi yang memakai konsep bunga.

Riba memiliki berbagai macam jenis. Pertama, riba qardh yaitu suatu manfaat atau tingkat kelebihan tertentu yang disyaratkan terhadap yang berhutang (muqtarid). Kedua, riba fadl yaitu pertukaran antar barang sejenis dengan kadar atau takaran yang berbeda dan barang yang dipertukarkan termasuk kedalam berang ribawi. Ketiga, riba nasi'ah yaitu penangguhan atas penyerahan atau penerimaan jenis barang ribawi yang diperlukan dengan jenis barang ribawi lainnya. Riba nasi'ah terjadi karena adanya perbedaan, perubahan atau tambahan antara yang diserahkan saat ini dan yang diserahkan kemudian. Keempat, riba yad yaitu tambahan atas utang yang dibayar lebih dari pokoknya karena peminjam tidak mampu membayar utangnya pada waktu yang telah ditentukan, biasanya tambahan ini bertambah sesuat dengan lama waktu si peminjam membayar utangnya.

Landasan tentang riba terdapat dalam surat al-Baqarah ayat 278-279 yaitu:

يأيهاالذين ءامنوا اتقو الله ودروا مابقى من الربوا ان كنتم مؤمنين,فان لم تفعلوا فأذنوا بحرب مسن الله ورسوله وان تبتم فلكم رعوس أمو الكم لاتظلمون و لاتظلمون

Artinya: Wahai orang-orang yang beriman! Bertakwalah kepada Allah dan tinggalkanlah sisa riba (yang belum dipungut) jika kamu orang yang beriman, jika kamu tidak melaksanakannya, maka umumkanlah 
Jurnal Riset Agama, Volume 1, Nomor 1 (April 2021): 197-208

Weni Luthfiani Fauziah/Dampak Riba mendatangkan Kebinasaan: Sebuah Tinjaun Hadis

perang dari Allah dan Rasul-Nya tetapi juka kamu bertaubat maka kamu berhak atas pokok hartamu kamu tidak berbuat zalim (merugikan) dan tidak dizalimi (dirugikan).

Dalam ayat ini, Allah swt. menganjurkan kepada hamba-Nya yang beriman untuk bertakwa dan menjaga amal perbuatan supaya benar-benar berada di jalan Allah. Dan Allah juga melarang hambanya untuk melakukan perbuatan riba. Sedikit atau banyaknya riba masih menjadi perdebatan, namun meskipun sedikit pengambilan tambahan tetap dilarang.

\section{Hadis tentang Riba}

Terdapat hadis Nabi Saw. berkenaan dengan riba pada Shahih Muslim Nomor 2995:

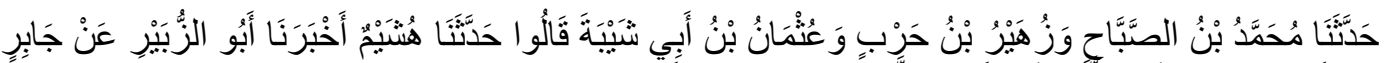

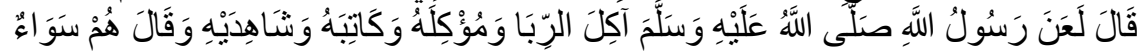

Telah menceritakan kepada kami Muhammad bin Shabah dan Zuhair bin Harb dan Utsman bin Abu Syaibah mereka berkata: telah menceritakan kepada kami Husyaim telah mengabarkan kepada kami Abu Az-Zubair dari Jabir dia berkata: "Rasulullah Saw. melaknat pemakan riba, pemberi makan riba, dan juru tulisnya dan saksi-saksinya. Dia berkata: mereka semua sama.

Mula-mula dilakukan pencarian melalui aplikasi hadis tentang kata kunci "riba" hingga ditemukan hadis pada kitab Shahih Muslim Nomor 2995, sebagaimana dikemukakan terdahulu.

Tabel 1 Daftar Rawi Sanad

\begin{tabular}{|c|c|c|c|c|c|c|c|c|}
\hline \multirow[t]{2}{*}{ No. } & \multirow[t]{2}{*}{$\begin{array}{l}\text { Rawi } \\
\text { Sanad }\end{array}$} & \multicolumn{2}{|c|}{$\begin{array}{c}\text { Lahir/Wa } \\
\text { fat }\end{array}$} & \multirow[t]{2}{*}{ Negeri } & \multirow[t]{2}{*}{ Kuniyah } & \multicolumn{2}{|c|}{$\begin{array}{l}\text { Komentar } \\
\text { Ulama }\end{array}$} & \multirow[t]{2}{*}{ Kalangan } \\
\hline & & $\mathrm{L}$ & W & & & - & + & \\
\hline 1 & $\begin{array}{c}\text { Jabir bin } \\
\text { 'Abdullah } \\
\text { bin 'Amru } \\
\text { bin } \\
\text { Haram }\end{array}$ & & $78 \mathrm{H}$ & Madinah & $\begin{array}{c}\text { Abu } \\
\text { 'Abdullah }\end{array}$ & & -Shahabat & Shahabat \\
\hline 2 & $\begin{array}{l}\text { Muhamm } \\
\text { ad bin } \\
\text { Muslim } \\
\text { bin } \\
\text { Tidrus }\end{array}$ & & $126 \mathrm{H}$ & $\begin{array}{l}\text { Marur } \\
\text { Rawdz }\end{array}$ & $\begin{array}{c}\text { Abu Az- } \\
\text { Zubair }\end{array}$ & & $\begin{array}{l}\text {-Tsiqah } \\
\text { Hafidz } \\
\text {-Laisa bihi } \\
\text { ba's } \\
\text {-Shaduq } \\
\text { - } \\
\text { Disebutka }\end{array}$ & $\begin{array}{c}\text { Tabi'in } \\
\text { biasa }\end{array}$ \\
\hline
\end{tabular}


Jurnal Riset Agama, Volume 1, Nomor 1 (April 2021): 197-208

Weni Luthfiani Fauziah/Dampak Riba mendatangkan Kebinasaan: Sebuah Tinjaun Hadis

\begin{tabular}{|c|c|c|c|c|c|c|}
\hline & & & & & $\begin{array}{l}\mathrm{n} \text { dalam } \\
\text { ats tsiqah } \\
\text {-Tsiqah } \\
\text { shahabat } \\
\text {-Shaduq } \\
\text { tsiqah } \\
\text {-Tsiqa }\end{array}$ & \\
\hline 3 & $\begin{array}{l}\text { Husyaim } \\
\text { bin Basyir } \\
\text { bin Al- } \\
\text { Qasim bin } \\
\text { Dinar }\end{array}$ & $183 \mathrm{H}$ & Hait & $\begin{array}{l}\text { Ibnu Abi } \\
\text { Khazim }\end{array}$ & $\begin{array}{l}\text {-Tsiqah } \\
\text {-Tsiqah } \\
\text { imam } \\
\text {-Tsiqah } \\
\text {-Tsiqah } \\
\text { Sahahabat } \\
\text {-Tsiqah } \\
\text {-Tsiqah } \\
\text { Shahabat }\end{array}$ & $\begin{array}{l}\text { Tabi'iul } \\
\text { atba' tua }\end{array}$ \\
\hline 4. & $\begin{array}{l}\text { Muhamm } \\
\text { ad bin } \\
\text { Ash } \\
\text { Shahabah }\end{array}$ & $227 \mathrm{H}$ & Baghdad & Abu Ja'far & $\begin{array}{l}\text {-Tsiqah } \\
\text { hafidz } \\
\text {-Tsiqah } \\
\text {-Tsiqah } \\
\text {-Tsiqah } \\
\text { hafidz } \\
\text {-Tsiqah } \\
\text { mashur } \\
\text {-Tsiqah }\end{array}$ & $\begin{array}{l}\text { Tabi'ul } \\
\text { atba' tua }\end{array}$ \\
\hline
\end{tabular}

Tabel 1 adalah daftar rawi dan sanad dari hadis yang sedang diteliti. Pemasangan seluruh rangkaian jalur sanad dapat dilihat pada bagan di atas. Hal ini dilakukan agar lebih memudahkan melihat posisi setiap periwayat terhadap hadis tersebut. Hadis yang dapat di jadikan hujjah adalah hadis yang derajatnya shahih. Para ulama bersepakat bahwa ada lima syarat yang harus dipenuhi sebuah hadis agar dapat dikatakan hadis shahih. Kelima syarat itu diantaranya: sanadnya bersambung, perawi 'adil dan dhabit, terhindar dari unsur syadz dan 'illat (Nadhiran, 2014). Penilaian umum terhadap sanad hadis riwayat Muslim sesuai kesepakatan sebagian besar ulama (ijma' ulama) adalah shahih. Hal ini disebabkan ittishal assanad dan rijal al-hadisnya mayoritas ulama menilai tsiqah (Muhammad Amar Adly, 2020). Hadis ini diriwayatkan para Imam hadis yang sangat banyak diantaranya: Imam Ahmad bin Hanbal ra. dalam Musnadnya, dalam Baqi Musnad Al-Muktsirin Nomor 13744, Imam Abu daud dalam Sunannya, kitabjual beli bab makan riba Nomor 2895. Selain itu juga hadis ini memiliki syahid diantaranya dari jalur sahabat Abdullah bin Mas'ud dan Ali bin Abi Thalib yang diriwayatkan oleh Imam Turmudzi dalam Jami'nya, Imam Nasa'i dalam Sunannya, Imam Abu Dauz dalam Sunannya, Imam Ahmad bin Hanbal dalam Musnadnya dan Imam Ad-Darimi dalam Sunannya (Tho'in, 2016). Penulis menganalisis matan hadis diatas berdasarkan kaidah yang dikemukakan oleh M. Syuhudi Ismail, dan dapat 
Jurnal Riset Agama, Volume 1, Nomor 1 (April 2021): 197-208

Weni Luthfiani Fauziah/Dampak Riba mendatangkan Kebinasaan: Sebuah Tinjaun Hadis

dikategorikan sebagai hadis yang memiliki redaksi kalimat yang teratur (tidak syadz) dan mengacu kepada nash yang lebih kuat yaitu Al-Qur'an. Dan hadis diatas jika dilihat dari matan merupakan hadis yang tidak terdapat syadz dan ilat oleh karena itu hadis diatas merupakan hadis yang shahih (Sabir, 2010).

Para ulama telah memberikan syarah yakni penjelasan kandungan dan maksud hadis (Darmalaksana, 2020). Menurut Yusuf Qardhawi pemakan riba merupakan pihak pemberi piutang yang memiliki uang dan meminjamkan uang tersebut kepada peminjam dengan pengembalian yang lebih dari pokok. Pemberi makan riba merupakan orang yang meminjam sejumlah uang dan sepakat untuk mengembalikan pinjamannya dengan ada kelebihan dari pokok pinjaman. Golongan seperti ini akan mendapatkan dosa dan laknat dari Allah dan Rasul-Nya. Penulis riba merupakan orang yang mencatat transaksi pinjaman yang menimbulkan riba. Saksi riba merupakan orang yang menjadi saksi atas terjadinya transaksi riba. Penulis dan saksi riba juga akan dilaknat karena mereka terlah membantu melakukan perbuatan riba. Yusuf Qardhawi menggaris bawahi bahwa jika suatu keadaan yang mengharuskan seseorang untuk meminjam dan tidak dapat lagi dihindari sehingga orang tersebut harus terlibat dalam transaksi riba dimana ia harus memberikan bunga karena peminjamannya, maka dosanya hanya diberikan kepada pemakan ribanya (pemberi piutang) (Milah, 2016).

\section{Larangan dan Ancaman Perilaku Riba dalam Perspektif Hadis}

Sebagai pedoman hukum Islam dan sumber yang melengkapi AlQur'an, hadis Nabi Muhammad Saw. memainkan peranan penting dalam menjelaskan tinjauan hukum Islam atas suatu permasalahan, termasuk dalam perkara riba (Latif, 2020).

Riba merupakan perkara yang dilarang dan diharamkan oleh Allah Swt. sebagaimana hadis Nabi Saw. dalam kitab Shahih Bukhori Nomor 6531 sebagai berikut:

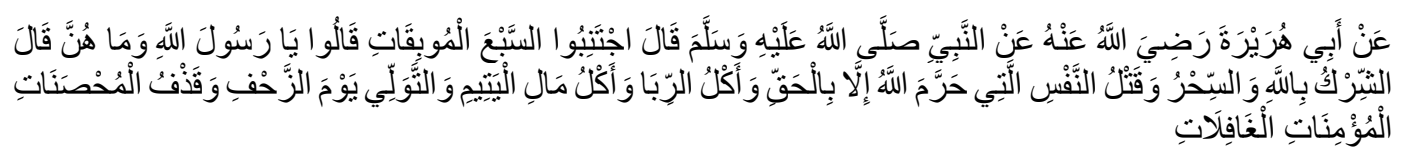

Dari Abi Hurairah ra. dari Nabi Saw. beliau bersabda:"Jauhilah oleh kalian tujuh perkara yang membinasakan, mereka (para sahabat) bertanya:"Wahai Rasulullah apakah (tujuh perkara) itu? Rasulullah menjawab:"Syirik kepada Allah, sihir, membunuh jiwa yang telah di haramkan oleh Allah kecuali dengan haq, memakan riba, memakan harta anak yatim, lari dari medan perang, dan menuduh seorang wanita mukmin yang suci berbuat zina. 
Jurnal Riset Agama, Volume 1, Nomor 1 (April 2021): 197-208

Weni Luthfiani Fauziah/Dampak Riba mendatangkan Kebinasaan: Sebuah Tinjaun Hadis

Hadis Rasulullah tersebut menunjukan bahwa riba itu diharamkan dan termasuk ke dalam salah satu perkara yang dapat membinasakan dan harus di jauhi. Dalam hadis tersebut riba disetarakan dengan syirik, sihir, membunuh, memakan harta anak yatim dan menuduh wanita mukmin berzaina. Dengan demikian hendaklah kita menjauhkan diri dari perilaku riba agar terhindar dari siksa Allah Swt.

Rasulullah Saw. bersabda dalam hadis lain mengenai larangan riba yaitu dalam Shahih Bukhari Nomor 2084 sebagai berikut:

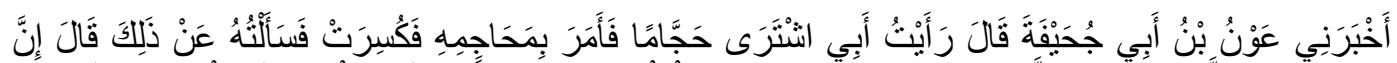

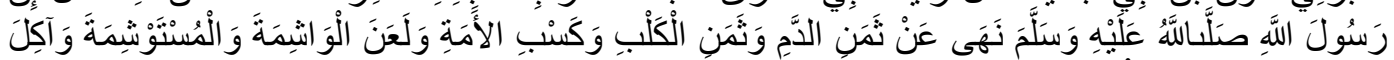

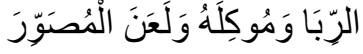

Telah menceritakan kepadaku Aun bin Abi Juhaifa ia berkata:"Aku melihat ayahku membeli seorang budak yang pekerjaannya membekam, kemudian ayahku menghancurkan peralatan bekam si budak tersebut. Aku bertanya kepada ayah mengapa beliah melakukan hal tersebut. Ayahku menjawab:"Sesungguhnya Rasulullah Saw. melarang untuk menerima uang dari transaksi darah, anjing, dan kasab budak perempuan, dan beliau melaknat pekerjaan membuat tato dan yang minta di tato, perilaku riba dan yang memberi riba serta beliau melaknat para pembuat gambar."

Perlu kita ketahui bahwa riba itu berkaitan dengan jual beli. Di dalam hadis Shahih Muslim Nomor 2965 diceritakan bahwa Rasulullah Saw. bersabda yang artinya:"Janganlah kalian melakukan jual beli emas dengan emas atau perak dengan perak kecuali jika sama beratnya, dan janganlah kalian melebihkan antara satu dengan yang lainnya dan jangan pula kalian melakukan transaksi sedangkan yang lain tidak ada di tempat, kecuali secara tunai." Hadis tersebut menjelaskan bahwa praktek jual beli dengan barang yang sejenis seperti emas, dengan emas, perak dengan perak harus dilakukan dengan ukuran, takaran dan timbangan yang sama. Apabila jual beli dilakukan dengan ukuran, takaran dan timbangan yang berbeda maka jual beli tersebut dikategorikan sebagai praktik riba kecuali barang yang diperjual belikan itu berbeda. Sekelompok fuqaha berpegang pada zahir hadis ini, bahwa riba itu hanya terbatas pada jenis barang yang tersebut dalam hadis saja. Implikasi dari pendapat ini bahwa selain jenis barang yang di sebutkan dalam hadis maka jenis lainnya tidaklah dikategorikan riba. Sedangkan kelompok yang terdiri dari Ammar, Abu Hanifah, dan Ahmad bin Hanbal, dalam suatu riwayat memandang bahwa segala sesuatu yang di jual dengan memakai takaran atau timbangan dapat dikategorikan sebagai riba. Sedangkan menurut Asy-Syafi'i dan Ahmad dalam suatu riwayat berpendapat bahwa riba itu memasuki emas, perak dan setiap makan dan minuman yang dijual dengan menggunakan takaran dan timbangan (Sabir, 2010). 
Jurnal Riset Agama, Volume 1, Nomor 1 (April 2021): 197-208

Weni Luthfiani Fauziah/Dampak Riba mendatangkan Kebinasaan: Sebuah Tinjaun Hadis

Praktek riba telah dilarang baik dalam Al-Quran maupun hadis Nabi. Larangan tersebut bukan tanpa sebab. Menurut Al-Far Al-Razi ada beberapa sebab dilarangnya dan diharamkannya riba diantaranya: Riba memungkinkan seseorang memaksakan pemilikan harta dari orang lain tanpa ada imbalan, riba dapat menghalangi pemodal untuk ikut berusaha mencari rezeki karena ia dengan mudah mendapatkan uang dari bunga, dengan riba biasanya si pemodal akan menjadi semakin kaya dan si peminjam akan menjadi semakin miskin (Setyawati, 2017).

Nabi Muhammad Saw. telah memperingati umat manusia dengan ancaman yang keras di dalam hadisnya mengenai riba, diantaranya sebagai berikut:

Dari Abu Hurairah ia berkata:"Rasulullah Saw. telah bersabda:"Riba itu mempunyai tujuh puluh tingkatan yang paling ringan (dosanya) adalah seperti seorang yang berzina dengan ibunya" (Sunan Ibnu Majah Nomor 2265).

Dari Abu Hurairah ia berkata:"Rasulullah Saw telah bersabda:"Pada malam isra mi'raj aku mendatangi suatu kaum yang mana perut mereka seperti rumah yang dihuni oleh sebuah ular dan dapat dilihat dari luar perut-perut mereka. Aku bertanya:"Wahai jibril, siapakah mereka itu? Jibril menjawab:"Mereka adalah pemakan riba" (Sunan Ibnu Majah Nomor 2264).

Dari Samrah bin Jundub ra. berkata:"Rasulullah Saw. telah bersabda:"Pada suatu malam aku melihat dua orang menemuiku dalam mimpi lalu keduanya membawa aku keluar menuju tanah suci. Kemudian kami berangkat hingga tiba di suatu sungan yang airnya dari darah. Di sungai itu ada seorang yang berdiri ditengah sungai dan satu orang lagi berada di tepinya sambil memegang batu dan laki-laki yang berada di tengah sungai menghampirinya dan setiap kali ia hendak keluar dari sungai itu maka laki-laki yang memegang batu melemparnya dengan batu tersebut ke arah mulutnya hingga ia kembali ke tempatnya semula (di tengah sungai) dan hal itu terus terjadi setiap kali ia hendak keluar dari sungai, ia akan dilempar dengan batu dan kembali ke tempatnya semula. Lalu aku bertanya:"Apa maksudnya ini?" maka orang di mimpiku itu menjawab:"Orang yang kamu lihat dalam sungai itu adalah pemakan riba" (Shahih Bukhari Nomor 1943).

Dari Abdullah bin Mas'ud ra. dari Nabi Saw. beliau bersabda:" Tidaklah suatu kaum menampakan riba dan zina, melainkan mereka telah menghalalkan terhadap diri mereka sendiri azab dari Allah Swt. (HR. Ibnu Majah).

Telah menceritakan kepada kami Muhammad bin Shabah dan Zuhair bin Harb dan Utsman bin Abu Syaibah mereka berkata: telah menceritakan kepada kami Husyaim telah mengabarkan kepada kami Abu Az-Zubair dari Jabir dia berkata: "Rasulullah Saw. melaknat pemakan riba, pemberi 
Jurnal Riset Agama, Volume 1, Nomor 1 (April 2021): 197-208

Weni Luthfiani Fauziah/Dampak Riba mendatangkan Kebinasaan: Sebuah Tinjaun Hadis

makan riba, dan juru tulisnya dan saksi-saksinya. Dia berkata: mereka semua sama (Shahih Muslim Nomor 2995).

Dari beberapa arti hadis yang telah diurakan tersebut dapat difahami bahwa ancaman Allah Swt. terhadap perilaku riba yakni dosanya seperti dosa berzina dengan ibunya, selain itu pelaku riba akan mendapat azab dan laknat Allah Swt.

Ada banyak hikmah yang dapat diambil dari adanya pelarangan perilaku riba diantaranya: Menjadikan pribadi manusia yang suka saling tolong menolong dan dengan sikap tolong menolong akan menciptakan ikatan persaudaraan yang semakin kuat dan mempererat ikatan silaturahmi, adanya larangan riba tidak merugikan orang-orang yang sedang kesusahan.

\section{Kesimpulan}

Riba merupakan pengambilan tambahan atau kelebihan dari suatu transaksiatau jual beli yang bertentangan dengan prinsip muamalah Islam sehingga dapat menguntungkan salah satu pihak. Riba erat sekali kaitannya dengan bank-bank konvensional, karena praktiknya banyak memakai konsep bunga. Riba memiliki empat macam yaitu riba qard, riba fadl, riba nasi'ah, dan riba yad. Dalam hadis Shahih Muslim tentang riba menyebutkan bahwa Allah Swt. dan Rasul-Nya melaknat pemakan riba dan pemberi makan riba. Berdasarkan ijma' ulama hadis tentang riba ini memiliki kedudukan shahih dan dapat dijadikan hujjah. Riba itu telah dilarang dan diharamkan oleh Allah Swt. dan merupakan perkara yang dapat membinasakan, pelakunya akan mendapatkan dosa yang besar dan laknat dari Allah Swt. Diharapkan penelitian ini memiliki implikasi manfaat bagi pengembangan khazanah pengetahuan Islam tentang larangan riba menurut hadis. Bagaimanapun penelitian ini memiliki keterbatasan dalam berbagai hal, yakni dalam penyusunan kerangka berfikir, penguasaan metode takhij dan syarah hadis, dan penerapan analisis sehingga dibutuhkan penelitian yang lebih komprehensif dan mendalam. Penelitian ini merekomendasikan pentingnya penyuluhan kepada khalayak muslim bahwaa riba itu dilarang dan diharamkan oleh Allah dan Rasul-Nya dan termasuk ke dalam perkara yang dapat membinasakan. 
Jurnal Riset Agama, Volume 1, Nomor 1 (April 2021): 197-208

Weni Luthfiani Fauziah/Dampak Riba mendatangkan Kebinasaan: Sebuah Tinjaun Hadis

\section{Daftar Pustaka}

Darmalaksana, W. (2020). Metode Penelitian Kualitatif Studi Pustaka dan Studi Lapangan Pre-print Digital Library UIN Sunan Gunung Djati Bandung, 1-6. http:/ / digilib.uinsgd.ac.id/32855/1/Metode\%20Penelitian\%20Kua litatif.pdf

Latif, Hamidah. (2020). Bahaya Riba dalam Perspektif Hadis. Jurnal Ilmiah Al Mu'Ashirah

Milah, Hayatul. (2016). Takhrij Hadis tentang Riba. Jurnal Asy-Syari'ah

Muhammad Amar Adly, Heri Firmansyah. (2020):Hadis-Hadis Tentang Riba dan Implementasinya dalam Sistem Perbankan. Alquds: Jurnal Studi Al Qur'an dan Hadis.

Munir, M. (2017). Konsep Riba dalam Islam:Analisis Tematik terhadap Konsep Riba dalam Al-Qur'an dan Hadis. research report fakultas ekonomi universitas islam negeri maulana malik ibrahim malang .

Nadhiran, H. (2014). Kritik Sanad Hadis: Telaah Metodologis. Jurnal Ilmu Agama UIN Raden Fatah.

Naufal, Ahmad. (2019). Riba dalam Al-Qur'an dan Strategi Menghadapinya. Al Maal : Journal of Islamic Economics and Banking

Sabir, Muhammad. (2010). Riba dalam Perspektif Hadis Nabi Saw. Jurnal Al-Syir'ah Vol. 8, No. 2

Sar'an, M.A. (2014). Riba dalam Perspektif Islam dan Sejarah. Iqtishadia: Jurnal Ekonomi dan Perbankan Syariah

Sari, Febrina. (2018). Konsep Riba dalam Kompilasi Hukum Ekonomi Syari'ah (Studi Analisis Teks KHES Indonesia). Al hurriyah: Jurnal Hukum Islam

Setyawati, Fitri. (2017). Riba dalam Pandangan Al-Qur'an dan Hadis. Al Intaj Fakultas Ekonomi dan Bisnis Islam

Tho'in, Muhammad. (2016). Larangan Riba dalam Teks dan Konteks (Studi atas Hadis Riwayat Muslim tentang Pelaknatan Riba). Jurnal Ilmiah Ekonomi Islam LPPM STIE AAS Surakarta.

Ulum, k. (2016). Hakikat Keharaman Riba dalam Islam. Jurnal ekonomi syariah universitas islam lamongan . 
Jurnal Riset Agama, Volume 1, Nomor 1 (April 2021): 197-208

Weni Luthfiani Fauziah/Dampak Riba mendatangkan Kebinasaan: Sebuah Tinjaun Hadis

Halaman ini sengaja dikosongkan 